\title{
Construção de Ambientes Interativos de apoio à reflexão docente aplicados à Teoria da Aprendizagem Significativa
}

\author{
Izabela Cristina Nere Rodrigues Cardoso, Thiago Canabrava Moreira, \\ Vitor Bertulucci Borges, Vandor Roberto Vilardi Rissoli \\ Engenharia de Software - Universidade de Brasília \\ Faculdade do Gama (FGA) - Gama Leste, Brasília - DF \\ \{cizabelacristina, vandorissoli\}@gmail.com
}

\begin{abstract}
The technology advances increasingly, making new demands of skills arise in various areas of society. Among the many areas that use technological resources to support their activities, this work highlights one of the most important in the formation of human beings, the Education. The combination of appropriate technologies to educational processes provides new interactive environments and can enhance continuing education. Thus, this combination, carried out in a manner consistent with the educational objectives, combines some technological advantages to promote didactic and pedagogical aspects that can be supported by technological resources for the implementation of a quality education.
\end{abstract}

Resumo. A tecnologia avança cada vez mais, fazendo com que surjam novas demandas de habilidades nos vários âmbitos da sociedade. Entre as diversas áreas que empregam recursos tecnológicos no apoio às suas atividades, este trabalho destaca uma das mais importantes na formação do ser humano, a Educação. A combinação de tecnologias adequadas aos processos educacionais fornece novos ambientes interativos e pode potencializar a educação continuada. Assim, essa combinação, realizada de maneira condizente aos objetivos educacionais, alia algumas vantagens tecnológicas para promover aspectos didático-pedagógicos que podem ser apoiados por recursos tecnológicos para a realização de uma educação de qualidade.

\section{Introdução}

A análise das práticas docentes em relação às necessidades da sociedade e $\mathrm{o}$ desenvolvimento tecnológico permite uma vasta reflexão sobre o assunto relacionado aos processos educacionais. Dessa forma, pesquisadores de diferentes áreas se envolvem nessa reflexão, trabalhando de maneira multidisciplinar e interativa, a fim de encontrar soluções pertinentes aos atuais desafios educacionais, facilitando o ensino de assuntos que por vezes podem ser considerados complexos para o aprendizado dos estudantes.

Em um mundo cada vez mais conectado, onde as crianças aprendem a navegar em dispositivos digitais praticamente na mesma velocidade com a qual aprendem a ler, os docentes precisam inovar nas metodologias de ensino, a fim de garantir a disseminação do conhecimento de forma mais interessante aos aprendizes, e também, mais eficiente, visto que o uso da tecnologia na educação proporciona diversas vantagens no processo ensino-aprendizagem, que vão desde aspectos pessoais, como motivação de alunos e professores, e a interação entre os mesmos, até aspectos didáticos, como a exploração de 
V Congresso Brasileiro de Informática na Educação (CBIE 2016)

Anais dos Workshops do V Congresso Brasileiro de Informática na Educação (CBIE 2016)

conteúdos, a contribuição na aprendizagem, dentre outros aspectos que podem ser observados na Figura 1.

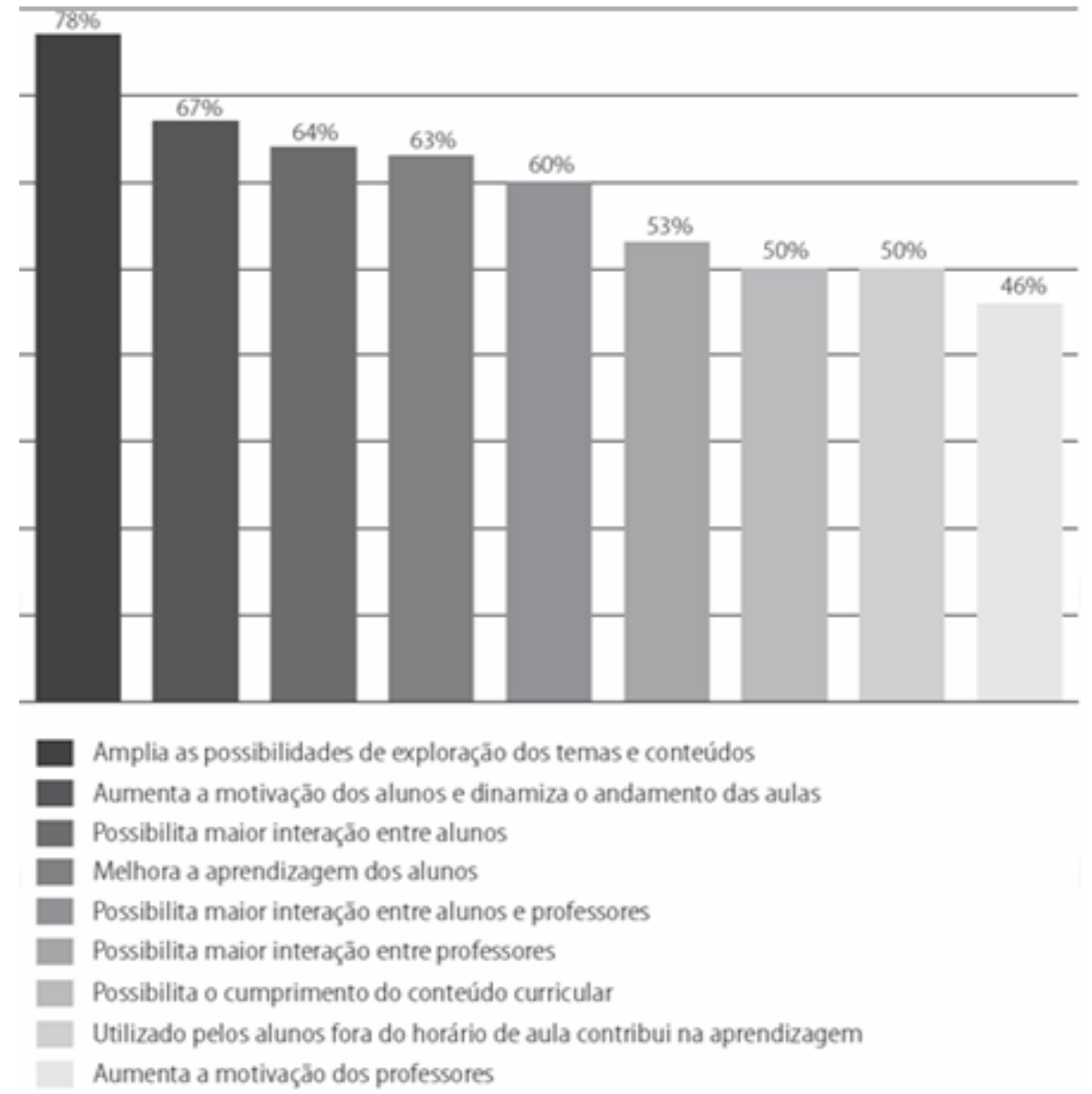

Figura 1. Vantagens no uso da tecnologia nas escolas (LOPES et al., 2009).

Com isso, a área da Educação se tornou um foco de ações e eventos que objetivam incentivar os educadores à reflexão sobre suas práticas didático-pedagógicas. Diante dessas ações, foi apresentado este trabalho que almeja incentivar as reflexões e o estudo de metodologias educacionais e recursos tecnológicos que ofereçam apoio significativo ao processo ensino-aprendizagem, dentre essas metodologias a Teoria de Aprendizagem Significativa, proposta por Ausubel (1980), e a Monitoria Estudantil, fundamentada por Pestalozzi (ASSUNÇÃO, 2008), foram destacadas, permitindo que os professores do ensino básico (anos finais do fundamental, ensino médio e técnico) do Distrito Federal tenham acesso a algumas metodologias de aprendizagem que trabalham associadas às tecnologias modernas para realização de um processo educacional personalizado dos discentes, bem como forneça assistência significativa e contínua aos principais envolvidos nesse processo (discentes, docentes, monitores e coordenados ou diretores).

\section{Metodologia}

Para a compreensão da Teoria de Aprendizagem Significativa (TAS) e da virtualização de conteúdos e tecnologias educacionais, foram utilizadas revisões bibliográficas de conteúdos relacionados ao assunto, tais como "Uma proposta metodológica de acompanhamento personalizado para Aprendizagem Significativa apoiada por um Assistente Virtual de Ensino Inteligente" (RISSOLI, 2007) e "Uma proposta de 
V Congresso Brasileiro de Informática na Educação (CBIE 2016)

Anais dos Workshops do V Congresso Brasileiro de Informática na Educação (CBIE 2016)

arquitetura de Sistema Tutor Inteligente baseada na Teoria das Experiências de Aprendizagem Mediadas" (RAABE, 2005), que unem as áreas de Educação e Tecnologia da Informação.

A revisão bibliográfica permitiu uma maior compreensão dos conceitos que seriam abordados no ambiente interativo e dos conteúdos que iriam compô-lo. Para acompanhar a compreensão dos conteúdos, foram criadas questões de cinco tipos diferentes, as quais foram, posteriormente, utilizadas na verificação da compreensão dos docentes. A Figura 2 apresenta uma janela do Sistema Tutor Inteligente SAE (Sistema de Apoio Educacional) que foi utilizado como tecnologia de apoio ao processo de reflexão e (re)construção de novas práticas docentes.

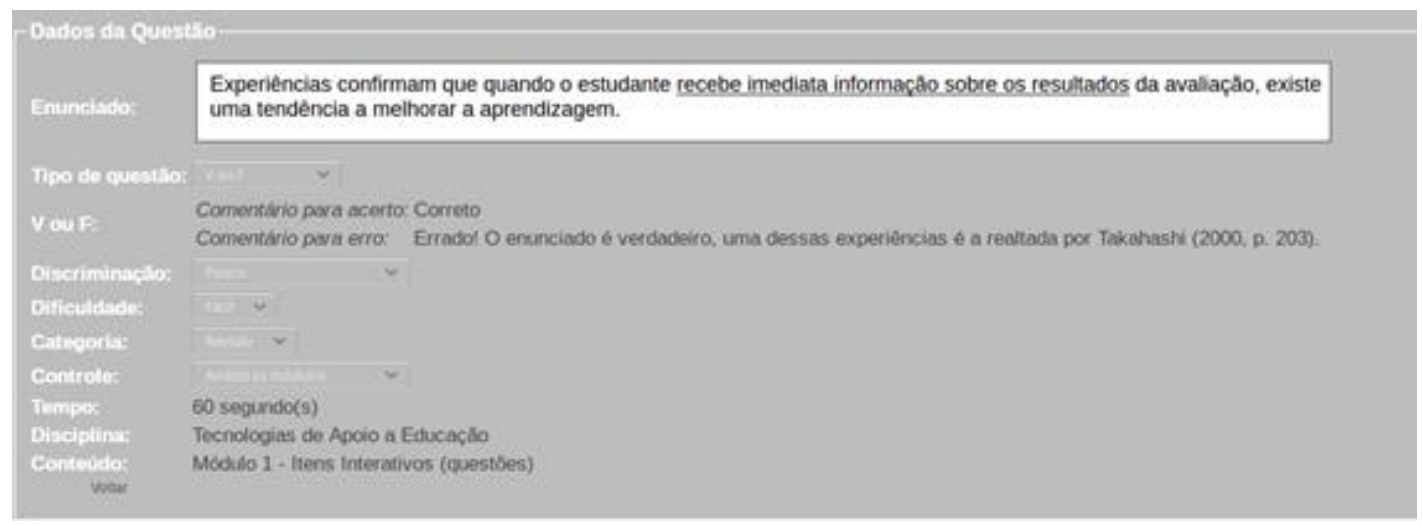

Figura 2. Janela interativa de criação de questões no SAE para posterior acompanhamento e verificação da assimilação dos conteúdos.

Uma vez que as questões foram avaliadas pelo professor responsável pelo projeto, e o mesmo validou o correto entendimento em relação aos conteúdos, uma próxima etapa pôde ser iniciada, a etapa de planejamento.

Para o planejamento do ambiente interativo foram utilizados protótipos evolutivos de alta fidelidade para planejar e validar o que viria a ser desenvolvido, pois segundo Basso e Sakaguti (2011), "um protótipo pode ajudar na descoberta e validação dos requisitos do sistema". Assim, os protótipos foram essenciais para auxiliar a visualizar como o produto final iria se comportar visualmente, sendo atualizados e revalidados de acordo com as mudanças ocorridas ao longo do desenvolvimento do projeto.

A prototipagem evolutiva ocorreu como ilustrado na Figura 3, sendo o professor orientador quem mantinha o contato com os possíveis usuários do ambiente, isto é, docentes e profissionais da área da Educação.

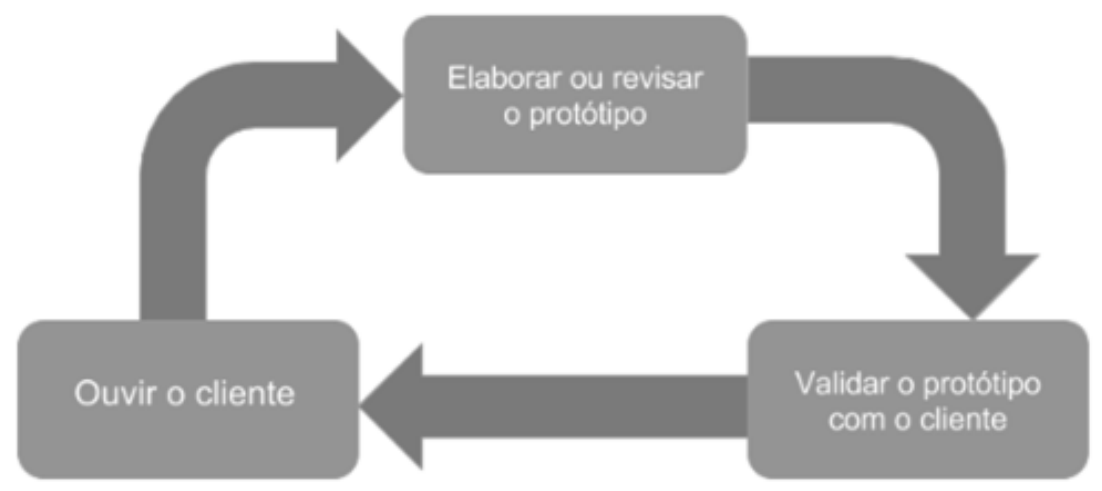

Figura 3. Esquema da prototipagem evolutiva do ambiente virtual em construção. 
V Congresso Brasileiro de Informática na Educação (CBIE 2016)

Anais dos Workshops do V Congresso Brasileiro de Informática na Educação (CBIE 2016)

Portanto, no processo utilizado para o desenvolvimento do ambiente interativo, o professor orientador atuou como cliente, representando os interesses dos usuários reais, pois, segundo Prates e Barbosa (2003) "um projetista não deve presumir que os usuários são como ele próprio". Dessa forma, foram realizadas reuniões com o orientador para identificar as demandas dos usuários.

Posteriormente, um protótipo do ambiente de disponibilização de conteúdo interativo era desenvolvido conforme estas demandas e novas reuniões eram realizadas para a validação e verificação do protótipo, repetindo o processo até obter uma versão do ambiente que atendesse às demandas, pois o projetista também não deve presumir que sua avaliação individual basta para atestar a qualidade de seu projeto (PRATES e BARBOSA, 2003). A Figura 3 ilustra o esquema de desenvolvimento do ambiente virtual e interativo de disponibilização de conteúdos instrucionais de apoio à reflexão docente, enquanto que a Figura 4 mostra uma das janelas desse ambiente virtual.

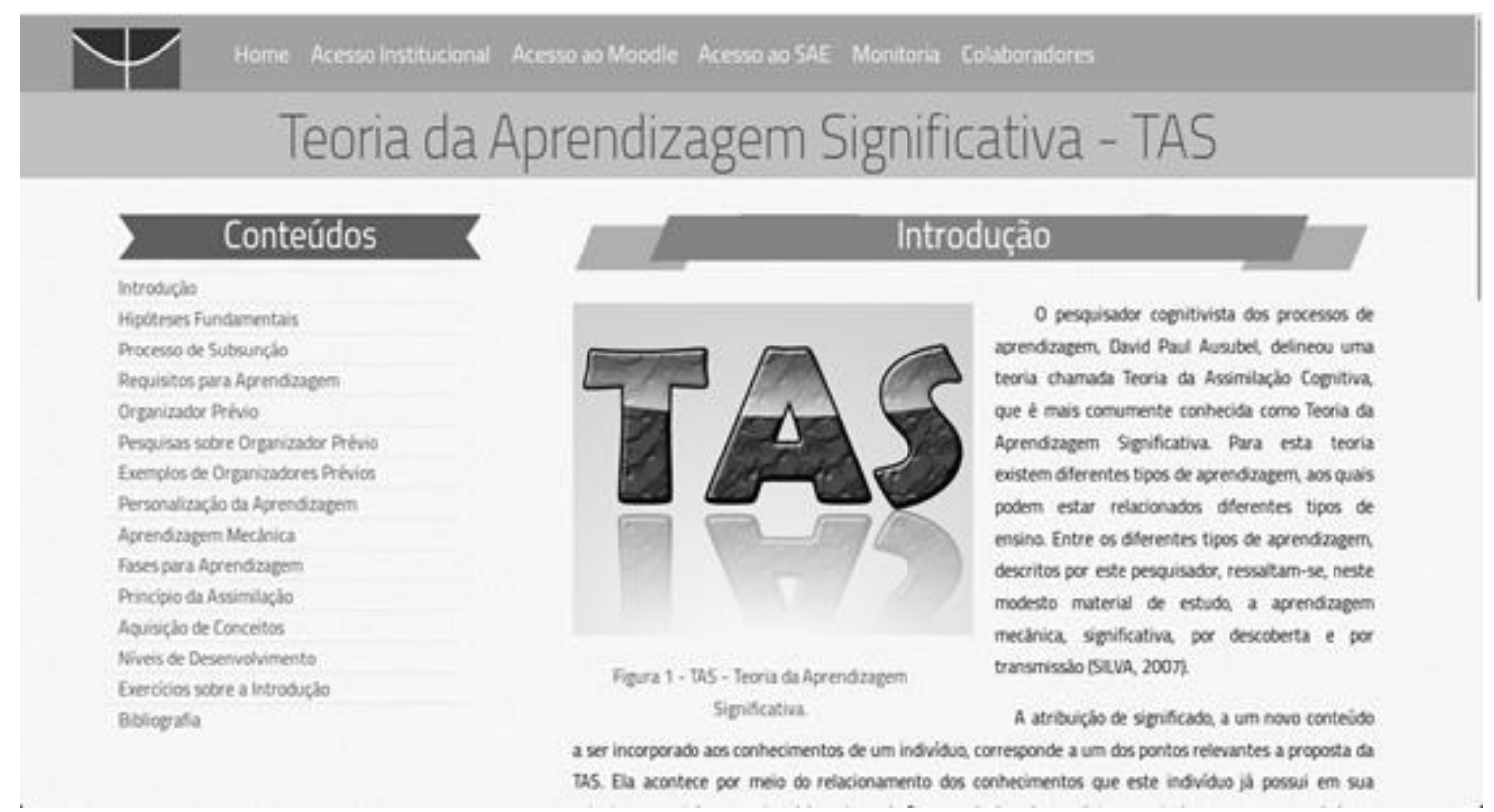

Figura 4. Design final do ambiente apresentando seus conteúdos letivos.

Com o planejamento concluído se iniciou o desenvolvimento real das páginas e recursos virtuais dos ambientes interativos de exposição dos conteúdos na Internet para o estudo de seus participantes. Esse desenvolvimento utilizou a linguagem HTML (Hyper Text Markup Language), XHTML (eXtensible Hyper Text Markup Language), CSS (Cascading Style Sheet) e Javascript, combinando recursos visuais adequados com possibilidades dinâmicas de interações aos seus diferentes usuários (MARCONDES, 2005).

Estas linguagens foram escolhidas por serem úteis no fornecimento de recursos para criar documentos com três componentes distintos e independentes, conforme define Furgeri (2006). Estes componentes são a estrutura, que define a organização da informação, o conteúdo, que representa a informação propriamente dita, e o estilo, que determina a maneira de melhor apresentação.

Dessa forma, o HTML foi escolhido para definir a estrutura e o conteúdo do documento, enquanto o CSS foi escolhido como complemento para melhorar a qualidade da apresentação das páginas desenvolvidas em HTML, além evitar repetições de código, 
V Congresso Brasileiro de Informática na Educação (CBIE 2016)

Anais dos Workshops do V Congresso Brasileiro de Informática na Educação (CBIE 2016)

facilitar a manutenção do mesmo e permitir mudanças em todo o ambiente através da alteração de uma declaração que está armazenada em um único arquivo.

Além destas tecnologias, também foi utilizada a ferramenta de edição de imagens Gimp para criação de algumas imagens usadas na ilustração do conteúdo e do ambiente virtual e instrucional.

$\mathrm{Na}$ fase de teste e manutenção, as páginas desenvolvidas foram revisadas, a fim de detectar erros de português, de digitação, erros nos padrões de design estabelecidos para o ambiente e inconsistências no conteúdo, principalmente.

Além disso, também foi planejado e efetivado certo suporte aos usuários iniciais desse ambiente, pois com base em Rezende (2005), a implantação do sistema também é uma fase de desenvolvimento do software, e a mesma inclui a capacitação e o treinamento de seus usuários. Esta capacitação se deu por meio da monitoria estudantil realizada por agentes humanos, que estavam disponíveis à interação nesse curso de forma totalmente virtual, usando ferramentas síncronas e assíncronas disponíveis no Ambiente Virtual de Aprendizagem (AVA). Com esse AVA (Moodle), utilizado na realização do curso, o objeto de aprendizagem estava completo para o apoio instrucional e interativo fornecido aos docentes e coordenadores pedagógicos que participaram desse estudo reflexivo e cooperativo envolvendo algumas tecnologias de apoio educacional.

Essa classificação, do objeto de aprendizagem estar completo aos anseios da equipe multidisciplinar que o desenvolvia, envolvia o AVA como o ambiente interativo responsável pela gestão do curso e fornecia o sentimento de "sala de aula virtual" aos docentes que estavam fazendo o curso e podiam interagir com seus colegas de turma.

O Sistema Tutor Inteligente SAE integrava esse objeto como responsável pelo acompanhamento individual de cada participante do curso, orientando as ações de seus aprendizes de maneira não invasiva, mas colaborando com a construção de um "caminho de aprendizagem" pertinente ao estado cognitivo de cada participante em seus diferentes momentos interativos com esse software educacional. A Figura 5 mostra essa integração.

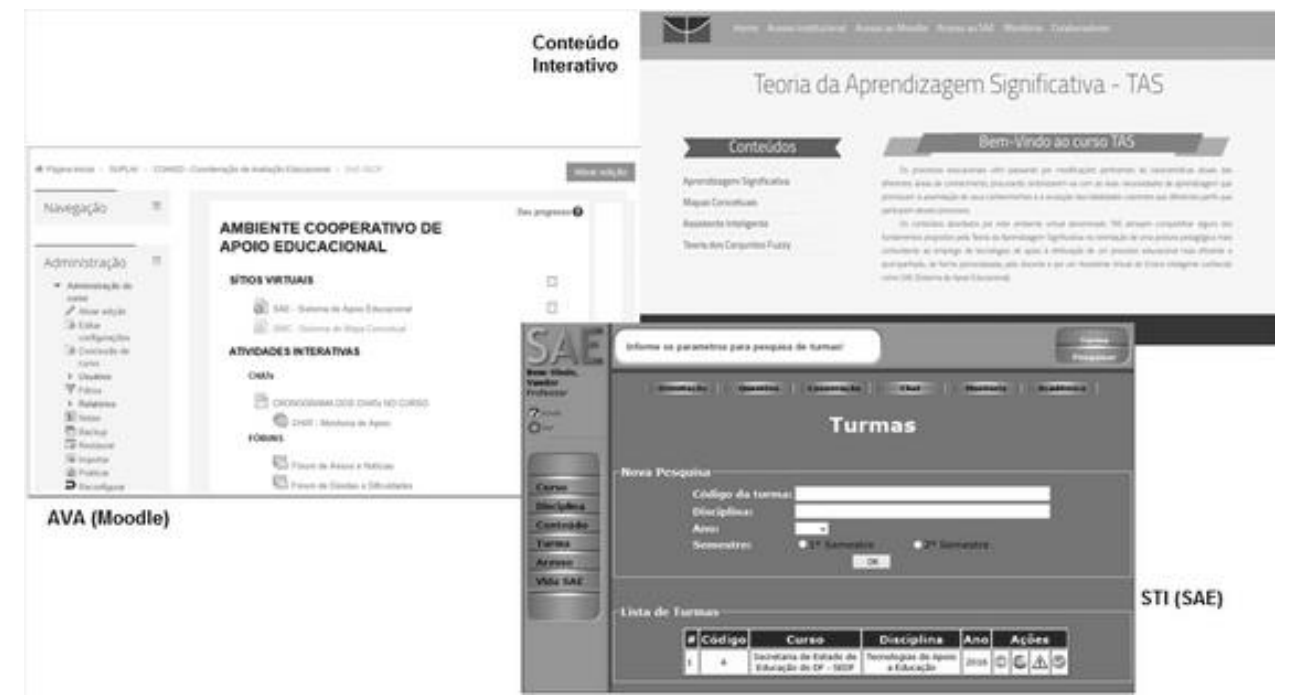

Figura 5. Esquema que representa as tecnologias AVA e STI integradas ao ambiente interativo do conteúdo letivo na formação do objeto de aprendizagem.

O esquema representativo da Figura 5 procura demonstrar a integração do ambiente interativo de exposição dos conteúdos do curso, acessado através das ligações 
V Congresso Brasileiro de Informática na Educação (CBIE 2016)

Anais dos Workshops do V Congresso Brasileiro de Informática na Educação (CBIE 2016)

virtuais disponíveis no Moodle, além das ferramentas síncronas (chat) e assíncronas (fórum) de interação entre o professor do curso e os seus participantes (docentes que são estudantes nesse curso) e entre os próprios participantes. O AVA (Moodle) torna-se assim responsável pela organização e gerenciamento dos recursos utilizados durante o curso, inclusive indicando o momento de exploração dos conteúdos, a agenda interativa com o professor e participantes, além das atividades fornecidas pelo próprio Moodle e pelo SAE.

O SAE faz parte dessa integração fornecendo orientação pedagógica baseada nas inferências resultantes do comportamento de cada participante durante o curso, além da colaboração dos monitores estudantis que estão disponíveis ao auxílio dos participantes. As recomendações de conteúdos complementares e possíveis colegas da turma que possam colaborar com a aprendizagem de um participante que esteja encontrando dificuldades em algum dos tópicos do conteúdo do curso também são recursos fornecidos pelo SAE em tempo real, atendendo ao ritmo do estudante (SANTOS e RISSOLI, 2011).

\section{Resultado}

A elaboração de conteúdos virtuais interativos, e visualmente adequados ao estudo de algumas metodologias educacionais e as tecnologias condizentes aos seus objetivos, possibilitou o fornecimento de apoio significativo para uma aprendizagem personalizada dos participantes da utilização dos ambientes fornecidos pelo objeto de aprendizagem, promovendo um espaço colaborativo para a reflexão docente.

Este apoio ocorreu através de um ambiente interativo composto pelo ambiente virtual de exposição de conteúdos sobre as metodologias educacionais e recursos tecnológicos interativos disponíveis no Moodle e no SAE que apoiaram a aprendizagem significativa, propiciando a gestão de dois cursos oferecidos aos professores e coordenadores pedagógicos da Secretaria de Estado de Educação do Distrito Federal (SEEDF). As janelas do ambiente virtual dos cursos estão ilustradas nas Figuras 6 e 7.

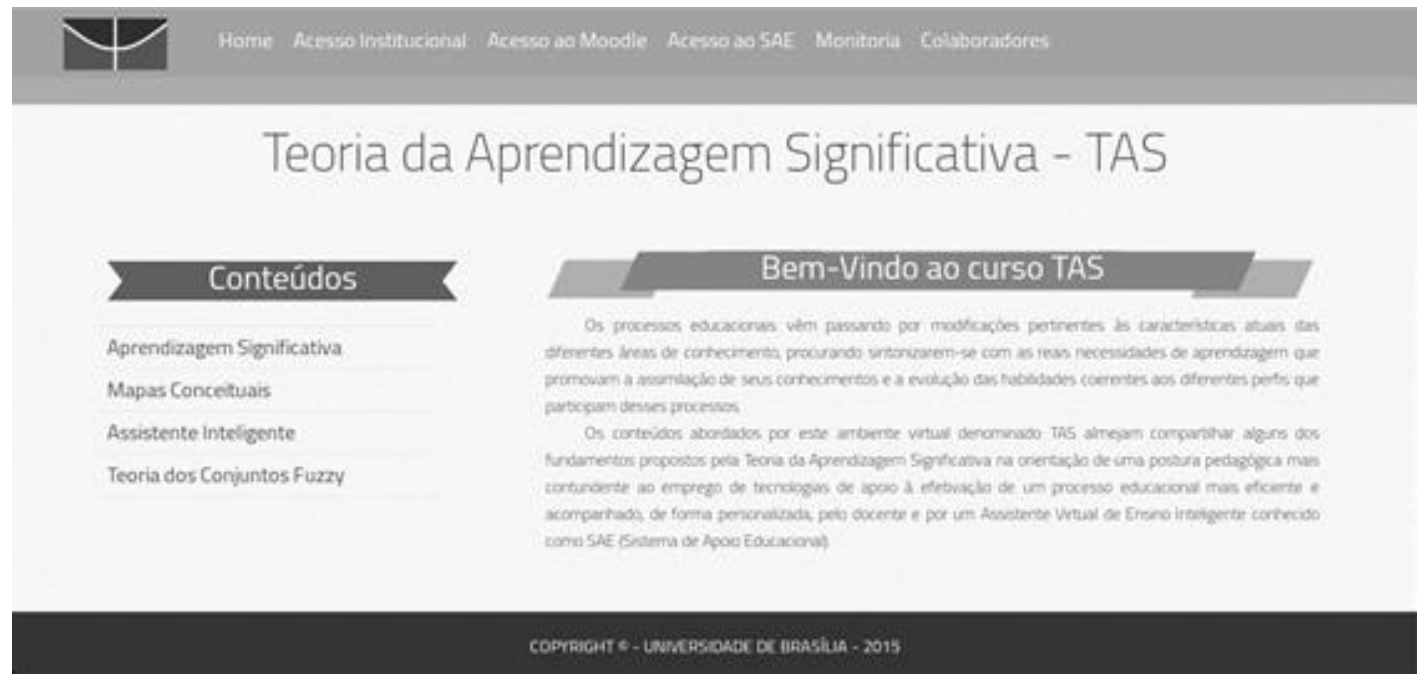

Figura 6. Janela inicial do ambiente virtual do primeiro curso de Tecnologias de Apoio à Educação para Aprendizagem Significativa.

Assim, dois cursos foram realizados na SEEDF promovendo a evolução do objeto de aprendizagem, que foi elaborado pela integração dos recursos tecnológicos para a exploravam dos conteúdos letivos, expostos em seus respectivos ambientes virtuais, além do Sistema Tutor Inteligente (SAE) e o Ambiente Virtual de Aprendizagem (Moodle) que 
V Congresso Brasileiro de Informática na Educação (CBIE 2016)

Anais dos Workshops do V Congresso Brasileiro de Informática na Educação (CBIE 2016)

garantiam o acompanhamento personalizado e a interação entre todos os participantes (aprendizes, monitores e o professor responsável pelo curso).

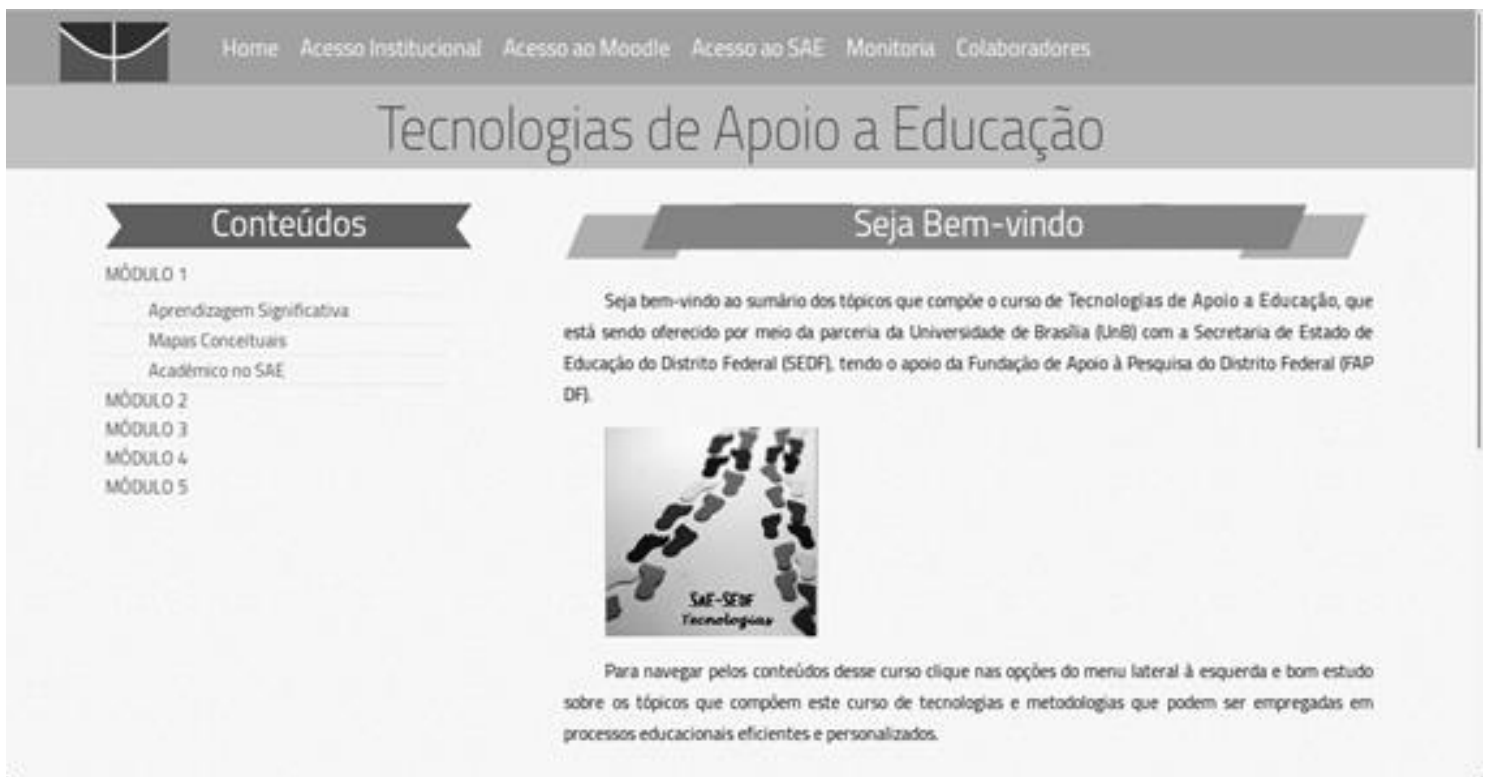

Figura 7. Janela inicial do ambiente virtual do segundo curso Tecnologias de Apoio à Educação realizado no primeiro semestre de 2016.

A integração dessas diferentes tecnologias (SAE e Moodle), na formação desse objeto de aprendizagem, pode ser observada na Figura 8, que indica o acesso ao SAE para realização de atividades de fixação do conteúdo estudado ou pelas usando das ligações virtuais superiores denominadas Acesso ao Moodle e Acesso ao SAE.

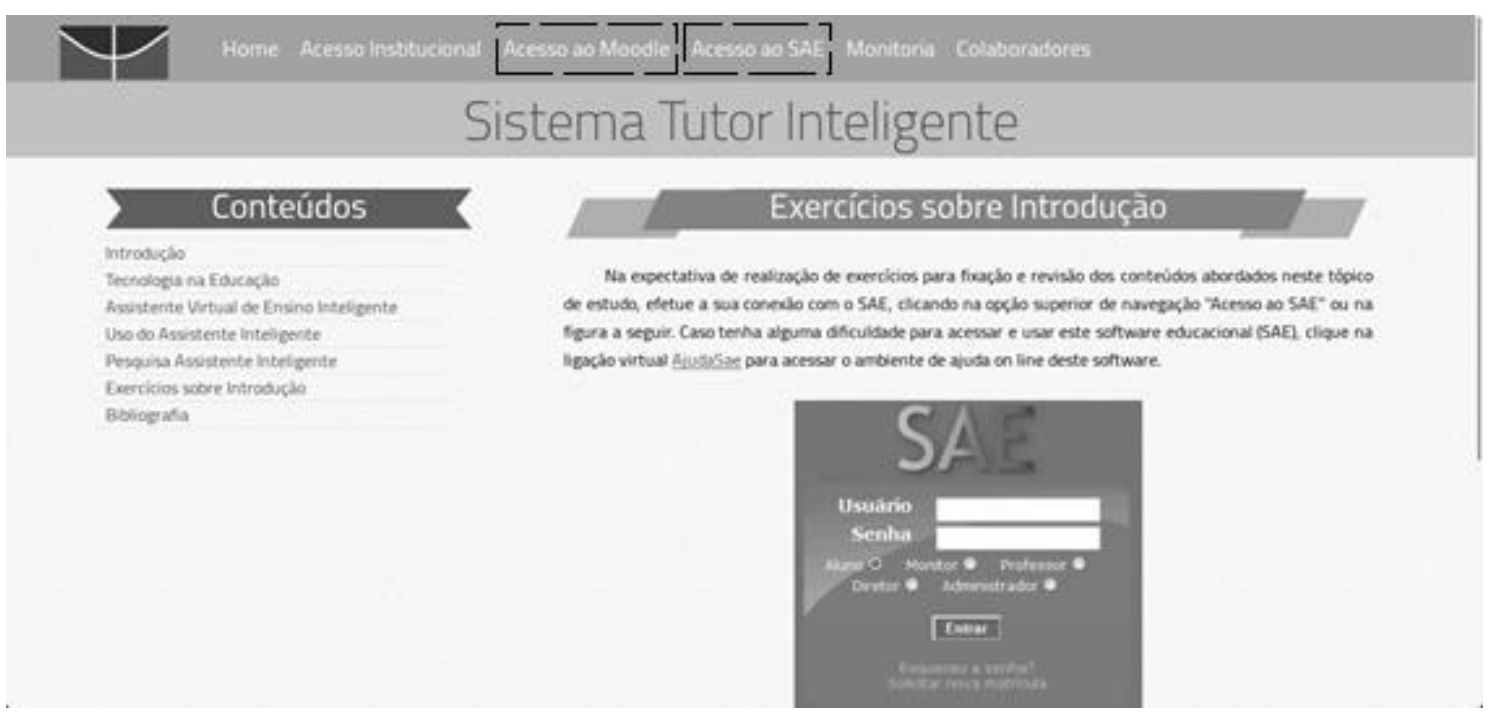

Figura 8. Janela de acesso ao SAE para resolução de exercícios interativos e destaque nas ligações virtuais de navegação ao Moodle e ao SAE.

A utilização desse ambiente propiciou aos docentes que estavam participando dos cursos a experiência da aplicação de alguns dos métodos explorados no processo educacional, em que estes docentes estavam como alunos e usaram das tecnologias empregadas no curso. É importante salientar que ao final de cada curso esses docentes eram convidados a participar de uma pesquisa que identificava o perfil do docente que 
V Congresso Brasileiro de Informática na Educação (CBIE 2016)

Anais dos Workshops do V Congresso Brasileiro de Informática na Educação (CBIE 2016)

estava concluindo o curso e a sua própria avaliação do curso, além das possibilidades de aplicação do que foi abordado em suas atividades acadêmicas.

Pouco mais de $17 \%$ dos docentes que começaram o curso participaram dessa pesquisa, onde a segunda edição do curso introduziu $25 \%$ desses docentes, que responderam à pesquisa, em sua primeira experiência com educação à distância. Entre esses docentes que responderam à pesquisa foi identificado que $62,5 \%$ ainda não tiveram uma experiência como professores que usam recursos mais comuns à educação a distância, levando-os assim a reflexões sobre suas posturas pedagógicas e contribuindo com uma possível "reconstrução" de suas práticas docentes.

Conforme os docentes avançavam nos módulos do curso, novos conhecimentos e habilidades ao uso desses recursos tecnológicos eram trabalhados com cada participante, promovendo reflexões educacionais mais exequíveis pela experiência que o próprio docente estava vivenciando. Esse tipo de prática permitiu que a experiência vivida por cada docente participante do curso fosse única, adequada ao envolvimento de cada um com o ambiente desenvolvido e relevante às reflexões de suas práticas.

Este fato se reflete nos dados obtidos ao final do curso, em suas duas edições, nos quais, a motivação dos professores são indicativos dos resultados alcançados. Alguns exemplos dessa motivação podem ser observados nos relatos efetivados na pesquisa proposta. Um professor concluinte do curso disse que "Acredito que esses conhecimentos podem ser usados para entender melhor o conceito de aprendizagem e uma maneira de usar tecnologia na aprendizagem individual".

Em outros dois relatos outros pontos interessantes são apontados pelos docentes participantes em coerência com a sua possível realidade:
"O curso é muito interessante em diversos aspectos, desde o conhecimento da Teoria da Aprendizagem Significativa, até a possibilidade de uso de uma tecnologia promissora no processo ensino- aprendizagem. Além disso, requer pouca disponibilidade de tempo, uma vez que é quase que inteiramente à distância."
"Porque considero um curso viável em recursos tecnológicos de apoio à aprendizagem, pois os alunos podem melhorar o seu desempenho em qualquer conteúdo abordado utilizando tais recursos. A disponibilidade do aluno acessar o SAE em qualquer momento, favorece um maior interesse no ritmo de estudos deles."

Além disso, alguns dos professores que terminaram o curso já estão usando com ao menos uma turma discente a tecnologia de apoio educacional oferecida pelo Sistema Tutor Inteligente SAE, havendo também a aceitação dos próprios alunos que gostaram da colaboração do SAE e até solicitam aos seus professores a disponibilização de novos itens (questões) para continuação do estudo sobre os conteúdos letivos e interação com o agente pedagógico animado presente no SAE (RISSOLI e SANTOS, 2013).

No depoimento de um dos docentes que já está utilizando o SAE com seus alunos, "O software dá oportunidade ao estudante de seguir seus estudos de forma mais autônoma, além de contribuir para a fixação dos conteúdos estudados", é possível notar a satisfação e o êxito para com as expectativas desse professor no uso de tecnologias no apoio aos seus processos educacionais. 
V Congresso Brasileiro de Informática na Educação (CBIE 2016)

Anais dos Workshops do V Congresso Brasileiro de Informática na Educação (CBIE 2016)

\section{Conclusão}

As novas demandas da Educação envolvem diferentes tecnologias em sua realização, atendendo às expectativas de agilidade e qualidade da sociedade atual. A área da Educação não é diferente das demais, que também estão evoluindo as novas demandas, sendo relevante a criação de espaços de convivência e troca de experiências aos docentes e discentes, que vivenciam diferentes contextos, mas que mutuamente podem contribuir com o sucesso de cada um no processo educacional.

Consciente dessa situação, foi alcançado o êxito do trabalho proposto, onde diferentes docentes encontraram um espaço colaborativo para aprendizagem e reflexões sobre suas práticas pedagógicas, além da oportunidade de obter novos conhecimentos e/ou habilidades sobre como integrar tecnologias em suas práticas, permitindo a exploração dos recursos atuais no processo ensino-aprendizagem.

Suscitando a interação e a troca de experiências, o ambiente tecnológico utilizado foi condizente com as expectativas dos organizadores e participantes. Essa situação pode ser confirmada pelo interesse de outras divisões da Secretaria de Estado de Educação do Distrito Federal em realizar novas edições do curso, dos professores concluintes já estarem usando novas práticas e tecnologias em suas turmas discentes, além de $100 \%$ dos participantes da pesquisa relatarem que indicariam o curso aos seus colegas docentes:

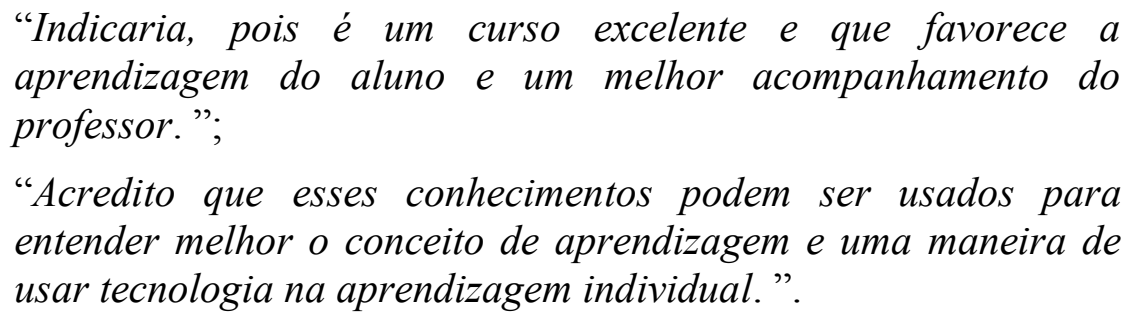

A principal contribuição desse trabalho foi fornecer aos professores do ensino básico (anos finais do fundamental, ensino médio e técnico) do Distrito Federal um ambiente interativo que propicie o estudo de algumas metodologias de aprendizagem que trabalham associadas com tecnologias modernas para realização de um processo educacional personalizado às necessidades discentes, bem como forneça assistência significativa e contínua aos principais envolvidos nesse processo educacional (discentes, docentes, monitores e coordenados ou diretores).

Acessando este ambiente os docentes da Secretaria (SEEDF) participaram da aplicação de alguns dos métodos lecionados nesse curso como alunos e usaram das tecnologias exploradas no curso. Através dessa experiência de cada professor o objetivo do curso pode ser alcançado, levando o docente participante a refletir sobre suas posturas pedagógicas e contribuindo com uma possível "reconstrução" de suas práticas docentes.

\section{Referências}

Assunção, B. S. B.; Lopes, E. S.; Rissoli V. R. V. (2008) Sistema Tutor Inteligente integrado a Monitoria Estudantil para elaboração de um Assistente Virtual de Ensino Inteligente. Anais do XXVIII Congresso da Sociedade Brasileiro de Computação. Workshop de Informática na Escola. Belém. p. 274-283.

Ausubel, D. P.; Novak, J. D. e Hanesian, H. (1980) Psicología Educacional. Rio de Janeiro: Editora Interamericana. 
V Congresso Brasileiro de Informática na Educação (CBIE 2016)

Anais dos Workshops do V Congresso Brasileiro de Informática na Educação (CBIE 2016)

Basso, T. e Sakaguti, S. T. (2011) Prototipação de interfaces: Reduzindo custos e melhorando o projeto. Centro Universitário da Grande Dourados. Especialização em Sistemas de Informação. Dourados, MS.

Furgeri, S. (2006) O papel das linguagens de marcação para a Ciência da Informação. Transinformação, Campinas, v. 18, n. 3, p. 225-239, sept./dec.

Lopes, R. D.; Ficheman, I.; Martinazzo, A. A. G; Correa, A. G. D. C; Venâncio, V.; Yin, H. T. e Biazon, L. C. (2009) O uso dos computadores e da internet nas escolas públicas de capitais brasileiras. Laboratório de Sistemas Integráveis/Departamento de Engenharia de Sistemas Eletrônicos/Escola Politécnica da Universidade de São Paulo.

Marcondes, C. A. (2005) HTML 4.0 Fundamental: A base para programação para Web. Érica.

Prates, R. O. e Barbosa, S. D. J. (2003) Avaliação de Interfaces de Usuário - Conceitos e Métodos. Anais do XXIII Congresso da Sociedade Brasileira de Computação. XXII Jornadas de Atualização em Informática (JAI). Campinas.

Raabe, A. L. A. (2005) Uma proposta de arquitetura de Sistema Tutor Inteligente baseada na Teoria das Experiências de Aprendizagem Mediadas. Tese (Doutorado) Universidade Federal do Rio Grande do Sul. Programa de Pós-Graduação em Informática na Educação, Porto Alegre, RS.

Rezende, D. A. (2005) Engenharia de Software e Sistemas de Informação. $3^{a}$ edição. Rio de Janeiro: Brasport.

Rissoli, V. R. V. e Santos, G. A. (2013) O Agente Pedagógico Animado MInA. Anais do Segundo Congresso Brasileiro de Informática na Educação. XXIV Simpósio Brasileiro de Informática na Educação (SBIE). Campinas.

Rissoli, V. R. V. (2007) Uma proposta metodológica de acompanhamento personalizado para aprendizagem significativa apoiada por um assistente virtual de ensino inteligente. Tese (Doutorado) - Universidade Federal do Rio Grande do Sul. Programa de Pós-Graduação em Informática na Educação, Porto Alegre, RS.

Santos, G. A. e Rissoli, V. R. V. (2011) Benefícios no Uso de um Assistente Inteligente no Ensino-Aprendizagem de Programação Computacional. Anais do XXII Simpósio Brasileiro de Informática na Educação. Aracaju. p. 2244-2253. 